\title{
Rift valley fever
}

INSERM

\section{Source}

INSERM. (1999). Orphanet: an online rare disease and orphan drug data base. Rift valley fever. ORPHA:319251

Rift Valley fever (RVF), caused by the Rift Valley fever virus (RVFV), is an arbovirus characterized by a usually self-limiting febrile illness but that in some cases can also manifest with thrombosis, vision loss, hemorrhages and/or neurological symptoms. 